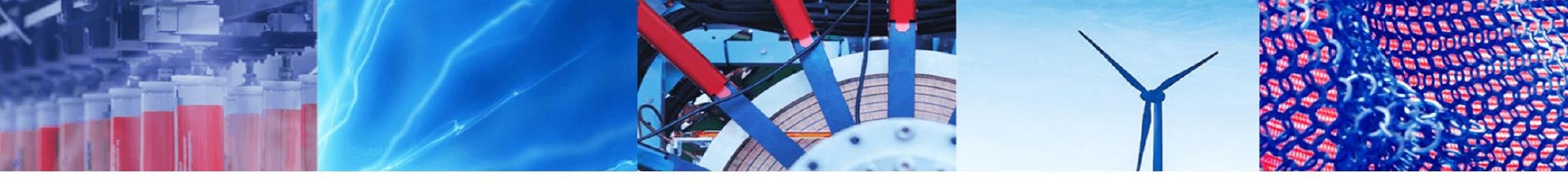

Research Article

\title{
Facile one-pot synthesis of water-soluble fcc FePt 3 alloy nanostructures
}

\author{
Melek Kızaloğlu Akbulut ${ }^{1}$. Christina Harreiß ${ }^{2} \cdot$ Mario Löffler $^{3,4} \cdot$ Karl J. J. Mayrhofer $^{3,4} \cdot$ Michael Schöbitz $^{5}$. \\ Julien Bachmann ${ }^{5} \cdot$ Erdmann Spiecker $^{2} \cdot$ Rainer Hock $^{6} \cdot$ Carola Kryschi $^{1}$ (i)
}

Received: 22 June 2020 / Accepted: 17 September 2020 / Published online: 28 September 2020

(c) The Author(s) $2020 \quad$ OPEN

\begin{abstract}
Proccessible $\mathrm{FePt}_{3}$ alloy nanoparticles with sizes smaller than $50 \mathrm{~nm}$ open the avenue to novel magnetic sensor, catalytic and biomedical applications. Our research objective was to establish a highly scalable synthesis technique for production of single-crystalline $\mathrm{FePt}_{3}$ alloy nanoparticles. We have elaborated a one-pot thermal decomposition technique for the synthesis of superparamagnetic $\mathrm{FePt}_{3}$ nanoparticles ( $\mathrm{FePt}_{3} \mathrm{NPs}$ ) with mean sizes of $10 \mathrm{~nm}$. Subsequent tiron coating provided water solubility of the $\mathrm{FePt}_{3} \mathrm{NPs}$ and further processibility as bidental ligands enable binding to catalyst surfaces, smart substrates or biosensors. The chemical composition, structure, morphology, magnetic, optical and crystallographic properties of the $\mathrm{FePt}_{3} \mathrm{NPs}$ were examined using high resolution transmission electron microscopy, high-angle annular dark field-scanning transmission electron microscopy, scanning transmission electron microscopy-energy-dispersive $\mathrm{X}$-ray spectroscopy mapping, Fourier transform infrared-attenuated total reflection, $\mathrm{X}$-ray powder diffraction, $\mathrm{X}$-ray photoelectron spectroscopy, vibrating sample magnetometry and UV-Vis absorption spectroscopy.
\end{abstract}

Keywords Iron-platinum alloy $\cdot \mathrm{FePt}_{3}$ nanoparticles $\cdot$ XPS · XRD analysis · Thermal decomposition route

\section{Introduction}

In recent years, bimetallic nanocrystals have received significant attention for nanoengineering, nanoelectronics and nanomedicine because of their particularly physical and chemical properties. Iron platinum alloy nanostructures in the $L 1_{0}, L 1_{1}$ and $L 1_{2}$ phases were engineered for applications as being magnetic sensors, catalysts, drug delivery tools, and biomedical imaging $[6,14,21,27,32$, 39]. Highly ordered FePt alloy nanocomposites exhibit an encouraging potential for ultrahigh density magnetic recording media and high-performance permanent magnets due to their uniaxial magnetocrystalline anisotropy, whereas chemically disordered FePt alloy nanoparticles promise applications in medical diagnostics (e.g. MPI, CT and MRI) $[4,14,23]$. FePt and $\mathrm{FePt}_{3}$ alloys may crystallize in three different crystal structures: $\mathrm{FePt}_{3}\left(\mathrm{~L}_{2}, \mathrm{AuCu}_{3}-\right.$ type cubic), FePt ( $\mathrm{L} 1_{0}, \mathrm{AuCu}$-type tetragonal) and $\mathrm{Fe}_{3} \mathrm{Pt}$ $\left(\mathrm{L}_{2}, \mathrm{AuCu}_{3}\right.$-type cubic), the magnetic properties of which depend on the synthesis procedure $[2,8,9,14]$. On the other hand, in the respective chemically disordered hightemperature FePt phase, the Fe and Pt atoms are randomly

$\triangle$ Carola Kryschi, carola.kryschi@fau.de; Melek Kızaloğlu Akbulut, melek.kizaloglu@fau.de| ${ }^{1}$ Department of Chemistry and Pharmacy and ICMM, Friedrich-Alexander University of Erlangen-Nürnberg, Egerlandstr. 3, 91058 Erlangen, Germany. ${ }^{2}$ Department of Materials Science and Engineering, Chair of Micro- and Nanostructure Research and Center for Nanoanalysis and Electron Microscopy, Interdisciplinary Center for Nanostructured Films, Friedrich-Alexander University of Erlangen-Nürnberg, Cauerstr. 3, 91058 Erlangen, Germany. ${ }^{3}$ Helmholtz Institute Erlangen-Nürnberg for Renewable Energy (IEK-11), Forschungszentrum Jülich GmbH, Egerlandstr. 3, 91058 Erlangen, Germany. ${ }^{4}$ Department of Chemical and Biological Engineering, Friedrich-Alexander University of Erlangen-Nürnberg, Egerlandstr. 3, 91058 Erlangen, Germany. ${ }^{5}$ Chair of Chemistry of Thin Film Materials, Friedrich-Alexander University of Erlangen-Nürnberg, Cauerstr. 3, 91058 Erlangen, Germany. ${ }^{6}$ Institute for Crystallography and Structural Physics, Friedrich-Alexander University of Erlangen-Nürnberg, Staudtstr. 3, 91058 Erlangen, Germany. 
distributed over the lattice sites and thus, exhibit isotropic magnetic behavior [27, 35]. The most common synthesis routes for preparing $\mathrm{FePt}$, $\mathrm{Fe}_{3} \mathrm{Pt}$ or $\mathrm{FePt}_{3}$ nanoparticles are the thermal decomposition technique and the polyol synthesis $[21,23]$. The face centered cubic (fcc) FePt phase can be transformed into the face centered tetragonal ( $\mathrm{fct}$ ) phase by high temperature annealing. Unfortunately, thermal annealing gives rise to agglomeration of FePt alloy nanocrystals which is accompanied by the emergence of undesired shapes and broad size distributions [13, 21]. The formation of FePt alloy nanocrystals depend on the growth from two different metals (Fe and $\mathrm{Pt}$ ) at distinct reaction temperatures [21]. Sun et al. synthesized FePt alloy nanocrystals by thermally decomposing $\mathrm{Fe}(\mathrm{CO})_{5}$ and $\mathrm{Pt}(\mathrm{acac})_{2}$ in the presence of the reducing agent oleyl amine and the surfactant oleic acid. Cytotoxic $\mathrm{Fe}(\mathrm{CO})_{5}$ can be substituted by iron(III) acetylacetonate or iron(III) oleate. Moreover high-boiling temperature solvents such as di- $n$-octyl ether or 1-octadecene are required for thermal decomposition synthesis routes. Polyol synthesis techniques are based on solvents such as tetraethylene glycol (TEG) and ethylene glycol (EG) which simultaneously serve as solvent and reducing agent for the metallic precursor $[23,33]$. One major drawback of these demanding synthesis techniques is the impossibility to adjust the growth of FePt alloy nanoparticles within a uniform crystal phase (fcc or fct).

In the present work, we have elaborated a straightforward synthesis route for chemically disordered fcc FePt nanocrystals. This one-pot synthesis is highly scalable for the preparation of superparamagnetic $\mathrm{FePt}_{3}$ nanoparticles ( $\mathrm{FePt}_{3} \mathrm{NPs}$ ) for future electronic and biomedical applications. The one-pot synthesis technique comprises the preparation of a $\mathrm{Pt}$ (II) precursor solution and subsequent formation of $\mathrm{FePt}_{3} \mathrm{NPs}$. Subsequent ligand exchange with tiron provided dispersion stability and water solubility of the $\mathrm{FePt}_{3} \mathrm{NPs}$ and moreover, facilitates their processing to thin magnetic films and their application as MRT/CT contrast agents in biomedical imaging. The tiron-coated $\mathrm{FePt}_{3}$ NPs were characterized by determining the average size, size distribution, morphology, crystallographic properties, colloidal stability, magnetic and optical properties. high resolution transmission electron microscopy (HRTEM), high-angle annular dark field-scanning transmission electron microscopy (HAADF-STEM), scanning transmission electron microscopy-energy-dispersive X-ray spectroscopy (STEM-EDX) mapping, Fourier transform infrared-attenuated total reflection (FTIR-ATR), X-ray powder diffraction (XRD), X-ray photoelectron spectroscopy (XPS), UV-Vis absorption spectroscopies were employed as microscopy and spectroscopy characterization techniques. The magnetic properties were examined using vibrating sample magnetometry.

SN Applied Sciences

A SPRINGER NATURE journal

\section{Experimental}

\subsection{Materials}

Dihydrogenhexachloroplatinate hexahydrate $\left(\mathrm{H}_{2} \mathrm{Cl}_{6} \mathrm{Pt} \times 6 \mathrm{H}_{2} \mathrm{O}, \geq 99,9 \%\right.$, Alfa Aesar), ethanol ( $\geq 99.8 \%$, Carl-Roth), oleic acid (90\%, Sigma-Aldrich), 1-octadecene (90\%, Sigma-Aldrich), tert-butylamine borane (TBAB, 97\%, Sigma-Aldrich), chloroform ( $\geq 99.9 \%$, SigmaAldrich), isopropanol ( $\geq 98 \%$, Sigma-Aldrich), tiron (97\%, Sigma-Aldrich), oleylamine (80-90\%, Acros Organics), $n$-hexane (95\%, VWR), iron(III) acetylacetonate $\left(\mathrm{Fe}(\mathrm{acac})_{3}\right.$, 97\%, Fluka) were used for the synthesis of the $\mathrm{FePt}_{3} \mathrm{NPs}$. All chemicals are commercially available and were used without further purification. In all syntheses, ultrapure milli-Q water (18 $\mathrm{M} \Omega$ ) was used.

\subsection{Preparation of the $\mathrm{Pt}(\mathrm{II})$ precursor solution}

$40.0 \mathrm{mg} \mathrm{H} \mathrm{H}_{2} \mathrm{Cl}_{6} \mathrm{Pt} \times 6 \mathrm{H}_{2} \mathrm{O}(0.077 \mathrm{mmol})$ were dissolved in $4.00 \mathrm{~mL}$ chloroform and $4.00 \mathrm{~mL}$ oleylamine $(12.2 \mathrm{mmol})$ were added. The precursor solution was stirred for $10 \mathrm{~min}$ under ambient conditions. $70.0 \mathrm{mg}$ TBAB $(0.804 \mathrm{mmol})$ and $1000 \mu \mathrm{L}$ oleylamine $(1.22 \mathrm{mmol})$ in $1000 \mu \mathrm{L}$ chloroform were mixed by sonication and added to the precursor solution. The mixture was stirred for $1 \mathrm{~h}$ at room temperature.

\subsection{Synthesis of $\mathrm{FePt}_{3} \mathrm{NPs}$}

Under argon atmosphere, the $\mathrm{Pt}$ (II) precursor solution in chloroform was added to a solution containing $15.0 \mathrm{~mL}$ 1-octadecene, $1.00 \mathrm{~mL}$ oleic acid $(3.15 \mathrm{mmol})$ and $1.00 \mathrm{~mL}$ oleylamine $(3.04 \mathrm{mmol})$. The reaction mixture was stirred for $30 \mathrm{~min}$ at $120^{\circ} \mathrm{C}$. Then $90.0 \mathrm{mg} \mathrm{Fe}(\mathrm{acac})_{3}$ $(0.255 \mathrm{mmol})$ dissolved in $5.00 \mathrm{~mL} 1$-octadecene were injected into the hot solution. The reaction mixture was heated to $320^{\circ} \mathrm{C}$ and boiled under reflux over $2 \mathrm{~h}$. After cooling down to room temperature the reaction mixture was exposed to air for $1 \mathrm{~h}$. The FePt ${ }_{3}$ NPs were precipitated by the addition of $60 \mathrm{~mL}$ isopropanol and collected by centrifugation $(11,000 \mathrm{rpm}, 10 \mathrm{~min})$. Afterwards the $\mathrm{FePt}_{3} \mathrm{NPs}$ were washed with ethanol and centrifugation and redispersed in $10 \mathrm{~mL} n$-hexane for storage.

\subsection{Tiron-coating of the $\mathrm{FePt}_{3} \mathrm{NPs}$}

$100 \mathrm{mg}$ tiron $(0.302 \mathrm{mmol})$ in $1.50 \mathrm{~mL}$ milli-Q water were added to a dispersion of $10 \mathrm{mg} \mathrm{FePt}{ }_{3} \mathrm{NPs}$ in $2.50 \mathrm{~mL}$ $n$-hexane. This biphasic $n$-hexane/water NP mixture was sonicated for $1 \mathrm{~h}$. Then $n$-hexane was removed using a 
rotary evaporator. The tiron-coated $\mathrm{FePt}_{3} \mathrm{NP}$ dispersion formed a stable aqueous solution.

\subsection{Microscopic and spectroscopic characterization}

HRTEM images were obtained using a Titan3 Themis 300 (FEl Company, Netherlands) equipped with a high-brightness field-emission gun (X-FEG), a monochromator system and two Cs-correctors (probe and image side) (CEOS $\mathrm{GmbH}$, Germany). The microscope operates at an acceleration voltage of $200 \mathrm{kV}$. The morphology and elemental composition of the $\mathrm{FePt}_{3} \mathrm{NPs}$ were examined by means HAADF-STEM using the Z-contrast. The STEM-EDX mappings were obtained using a Super-X detector for EDX spectroscopy. The HRTEM images were recorded using a FEI Ceta 16 M 4 K CMOS (complementary metal-oxide semiconductor) camera. HRTEM samples were prepared by dropping the $\mathrm{FePt}_{3} \mathrm{NP}$ dispersions on $\mathrm{Cu}$ grids coated with an ultrathin carbon film layer.

XRD patterns of $\mathrm{FePt}_{3}$ NPs powder samples were measured at room temperature using a Philips/Panalytical X-Pert Pro equipped with a copper radiation, $\left(\mathrm{K}_{\mathrm{a} 1}=0.154056 \mathrm{~nm}\right.$ and $\left.\mathrm{K}_{\mathrm{a} 2}=0.154439 \mathrm{~nm}\right)$. The XRD measurements were repeated 10 times. In addition, the Rietveld profile fitting of the XRD pattern of the $\mathrm{FePt}_{3} \mathrm{NP}$ sample was recorded by mounting in a silicon wafer to the XRD instrument at room temperature. Rietveld fitting was obtained by means of MAUD (Materials Analysis Using Diffraction) [15-18].

FTIR transmission spectra of the $\mathrm{FePt}_{3} \mathrm{NPs}_{\text {were }}$ recorded on an IR Prestige-21 spectrometer (Shimadzu, Japan) equipped with an attenuated ATR setup with a diamond/ZnSe crystal plate (Miracle ATR, Pike Technologies, U.S.A.).

XPS was conducted on a Quantera II microprobe (Physical Electronics Inc., Chanhassen, MN, USA) under ultrahigh vacuum conditions. The powder samples were mounted on a double-sided sticky tape to the sample holder. Monochromated Al Ka x-rays ( $1486.6 \mathrm{eV}$, source at $15 \mathrm{kV}$ and $50 \mathrm{~W}$ ) were focused on $200 \times 200 \mu^{2}$ homogeneously covered spots of the powder samples. The mostly nonconducting samples were neutralized by $\mathrm{Ar}^{+}$ions and electrons. The pure $\mathrm{Pt}$ and pure Fe reference samples were presputtered to clean the surface. Photoelectrons were detected at an analyzer pass energy of $280 \mathrm{eV}$ and $140 \mathrm{eV}$ and the number of sweeps for signal averaging were 3 and 25 for survey and high-resolution spectra, respectively. A peak at $284.8 \mathrm{eV}$ associated with C $1 \mathrm{~s}$ core-level was taken as a reference for the binding energy scale of the $\mathrm{FePt}_{3}$ NP samples.

The magnetic properties of the $\mathrm{FePt}_{3} \mathrm{NPs}$ were analyzed using a Quantum Design VSM-MPMS SQUID magnetometer at room temperature under an external magnetic field varied between $-5 \mathrm{~T}$ and $+5 \mathrm{~T}$.

\section{Results and discussions}

\subsection{HRTEM/HAADF-STEM/STEM-EDX analysis}

According to the HRTEM image in Fig. $1 \mathrm{a}$ the $\mathrm{FePt}_{3} \mathrm{NPs}$ are single crystalline and flower-like nanostructures with a mean size of $10 \mathrm{~nm}$. Furthermore, the HRTEM image (Fig. 1a, insert) exhibits lattice fringe spacings with $0.194 \mathrm{~nm}$ which identifies the (200) lattice plane of the face centered cubic (fcc) phase. Figure $1 \mathrm{~b}$ shows the HAADFSTEM image of the $\mathrm{FePt}_{3}$ NPs. The STEM-EDX mapping images visualize the homogeneous elemental distribution of Pt (green) and $\mathrm{Fe}$ (red) in the $\mathrm{FePt}_{3} \mathrm{NPs}$, and thereupon revealing their quasi-alloy $\mathrm{FePt}_{3}$ composition (Fig. 1C-e).

\subsection{XRD analysis}

The crystal structure of the $\mathrm{FePt}_{3} \mathrm{NPs}$ was elucidated by performing a powder XRD analysis. The XRD pattern in Fig. 2 displays prominent reflection peaks at $40.25,46.75$, 68.41 , and 82.34 which are assigned to the (111), (200), (220), (311) planes of the disordered fcc FePt ${ }_{3}$ phase with the space group Fm $3 \bar{m}$ (ICDD Ref: 001-089-2050) [29]. The Rietvield fit of the XRD data (Fig. 3) was obtained for the fcc phase of $\mathrm{FePt}_{3}$ and yielded the lattice constant $\mathrm{a}=0.3852 \mathrm{~nm}[15-18]$. The superlattice reflections (001) and (110) indicate a partially $\mathrm{L}_{2}$-ordered phase of $\mathrm{FePt}_{3}$. The average NP diameter was calculated to be $10 \mathrm{~nm}$ using the Debye-Scherrer equation [11], which agrees with the HRTEM analysis.

\subsection{FTIR-ATR spectra}

Oleic acid and oleylamine were used as stabilizing agents for the high-temperature synthesis of the $\mathrm{FePt}_{3} \mathrm{NPs}$. In the FTIR-ATR spectrum of the FePt ${ }_{3}$ NPs (Fig. 4, black solid line) the peaks at $2853 \mathrm{~cm}^{-1}$ and $2925 \mathrm{~cm}^{-1}$ were assigned to the symmetric and asymmetric $\mathrm{CH}_{2}$ stretching modes of oleic acid and oleylamine [5]. Water solubility and further processability of the $\mathrm{FePt}_{3} \mathrm{NPs}$ were achieved by tiron coating through ligand exchange. The binding modus of tiron was elucidated by analyzing the FTIR-ATR spectrum of tiron-coated FePt ${ }_{3}$ NPs (Fig. 4, red solid line). This FTIR-ATR spectrum exhibits the characteristic vibrational bands of tiron being bound via the catechol group at the $\mathrm{FePt}_{3}$ NP surface (Fig. 5). The broad band in the region of $3100-3600 \mathrm{~cm}^{-1}$ arose from the symmetric $\mathrm{O}-\mathrm{H}$ stretching vibrations of water. The vibrational peak at $1250 \mathrm{~cm}^{-1}$ and $1190 \mathrm{~cm}^{-1}$ are assigned to 

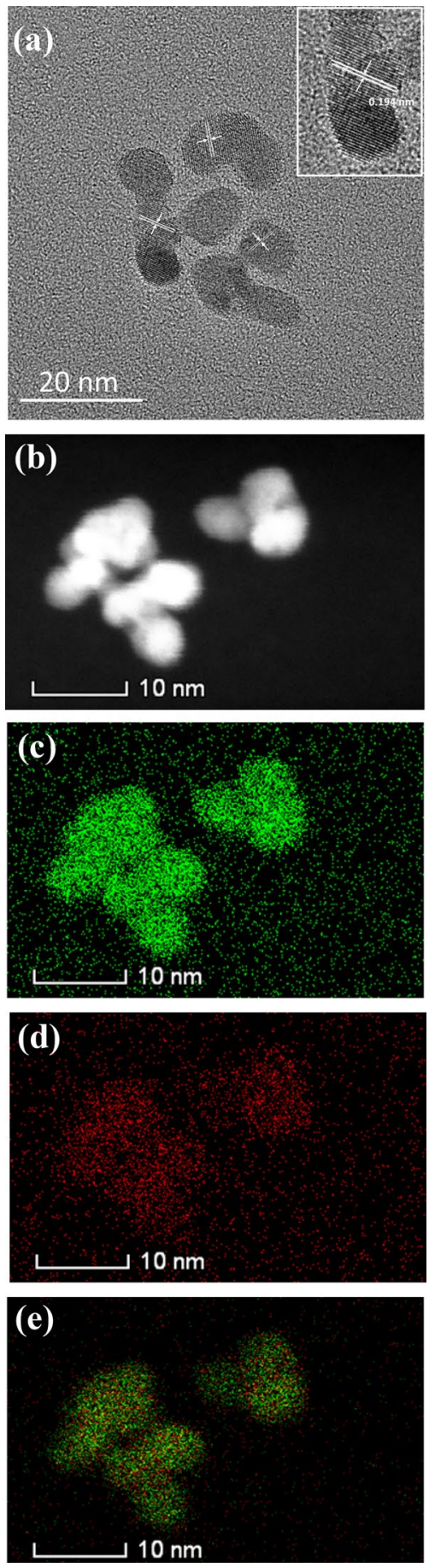

Fig. 1 a HRTEM image of the FePt ${ }_{3}$ NPs, $\mathbf{b}$ HAADF-STEM image of

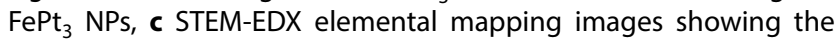
distribution of Pt (green) (Pt K-edge), d STEM-EDX elemental mapping images showing the distribution of $\mathrm{Fe}$ (red) (Fe K-edge), e merged image of the $\mathrm{FePt}_{3} \mathrm{NPs}$ of the elemental distribution of $\mathrm{Fe}$ (red) and Pt (green)

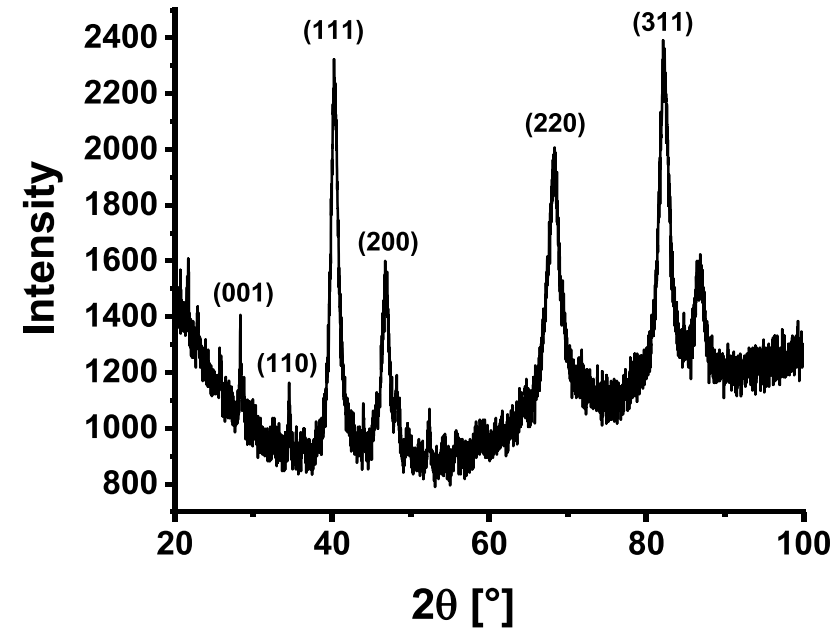

Fig. 2 XRD pattern of the $\mathrm{FePt}_{3} \mathrm{NPs}$

the asymmetric $\mathrm{S}=\mathrm{O}$ stretching vibration, and the band at $1031 \mathrm{~cm}^{-1}$ is ascribed to the symmetric $\mathrm{O}=\mathrm{S}=\mathrm{O}$ stretch of tiron [28]. The peak at $630 \mathrm{~cm}^{-1}$ identifies the $C-S$ stretching vibration. The peaks at $1596 \mathrm{~cm}^{-1}, 1459 \mathrm{~cm}^{-1}$ and $1426 \mathrm{~cm}^{-1}$ refer to the carbon-carbon stretching vibrations in the aromatic ring of the tiron [28].

\subsection{XPS analysis}

Figure 6 exhibits the Fe $2 p$ spectral region, namely the Fe $2 p 3 / 2$ and Fe $2 p 1 / 2$ multiplet for the $\mathrm{FePt}_{3}$ NPs and a pure metal Fe. The Fe $2 p$ spectral region consists of two peaks at approximately $712.8 \mathrm{eV}$ and $726.8 \mathrm{eV}$. The higher binding energy of the multiplet as compared to the metal reference $(707.0 \mathrm{eV}$ and $720.0 \mathrm{eV})$ and relatively high full width at half maximum of approximately $7 \mathrm{eV}$ for the peak at lower binding energy is often assigned to the presence of a multitude of different iron species in positive oxidation states such as iron oxides $[19,22,25$, $26,36,37]$. Qualitatively, the low binding energy tail of the NPs Fe $2 p 3 / 2$ component overlaps with the respective signal of the pure metal Fe at $707.0 \mathrm{eV}$. This effect is assigned to the presence of iron species that show only slightly higher binding energy as compared to metal Fe like for example Fe-Pt alloys [20,30].

Figure 7 shows the $\mathrm{Pt} 4 \mathrm{f}$ region comprising the $\mathrm{Pt} 4 \mathrm{f}$ $7 / 2$ and $P t 4 f 5 / 2$ multiplet. The Pt $4 f 7 / 2$ peak for the NPs is evidenced at $0.2 \mathrm{eV}$ towards lower binding energies as compared to the pure metal Pt at $71.2 \mathrm{eV}$. The effect, 
Fig. 3 The Rietveld profile fitting to the XRD pattern of the $\mathrm{FePt}_{3} \mathrm{NPs}$

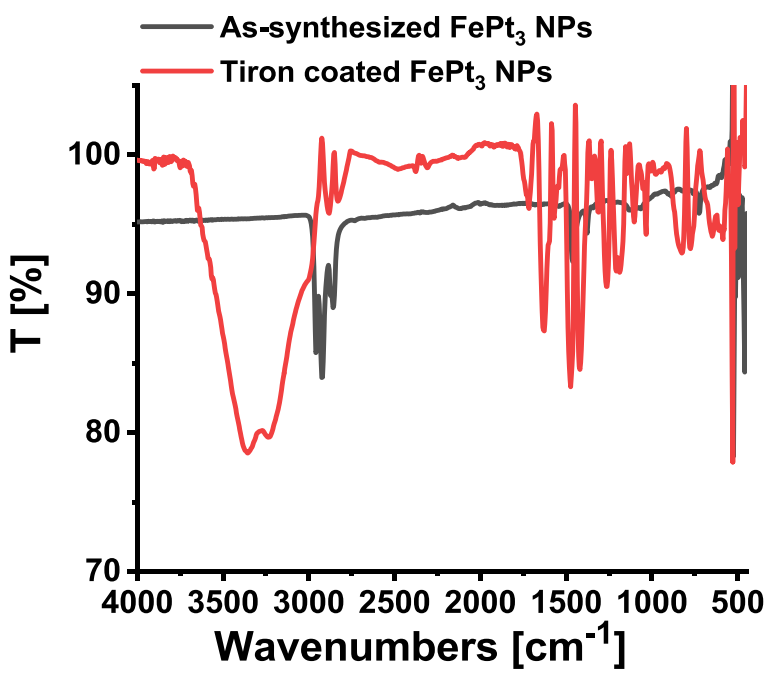

Fig. 4 FTIR-ATR transmission spectra of the as-synthesized $\mathrm{FePt}_{3}$ NPs (black solid line) and tiron-coated FePt ${ }_{3}$ NPs (red solid line)

which is just of the order of the uncertainty from the peak referencing of the spectrum, points to the formation of an interfacial Fe-Pt alloy and electron transfer at the interface towards the more electronegative Pt [20,
30]. The peak at higher binding energies $(75-78 \mathrm{eV})$ is assigned to the presence of precursor ions in the spectrum of the $\mathrm{FePt}_{3} \mathrm{NPs}$.

\subsection{UV-Vis absorption spectroscopy}

Figure 8 depicts the UV-Vis absorption spectrum of tironcoated $\mathrm{FePt}_{3} \mathrm{NPs}$ in water.

The UV-Vis absorption spectrum of tiron-coated $\mathrm{FePt}_{3}$ NPs displays a broad absorption band around $650 \mathrm{~nm}$ (Fig. 8) which is due to electron transfer from Pt to the antibonding $\pi$-molecular orbitals of tiron $[3,10,31,38]$. Valence tautomerization of tiron $(\mathrm{OH}$ to $=0)$ of tiron may also contribute to the emergence of these broad absorption band (Fig. 9) $[1,3,7,10,12,24,31,34,38]$.

Figure 10 presents the magnetization curve of a powder sample of tiron-coated $\mathrm{FePt}_{3} \mathrm{NPs}$ at room temperature under an external magnetic field varied between $-5 \mathrm{~T}$ and $+5 \mathrm{~T}$. The lack of any hysteresis loop verifies superparamagnetism of the $\mathrm{FePt}_{3} \mathrm{NPs}$ [29]. The $\mathrm{M}_{\mathrm{s}}$ value of the $\mathrm{FePt}_{3} \mathrm{NPs}$ is $35.90 \mathrm{emu} / \mathrm{g}$. The observed superparamagnetism reflects the chemical disorder of the $\mathrm{FePt}_{3}$ NPs.
Fig. 5 Tiron-coating of the $\mathrm{FePt}_{3} \mathrm{NPs}$

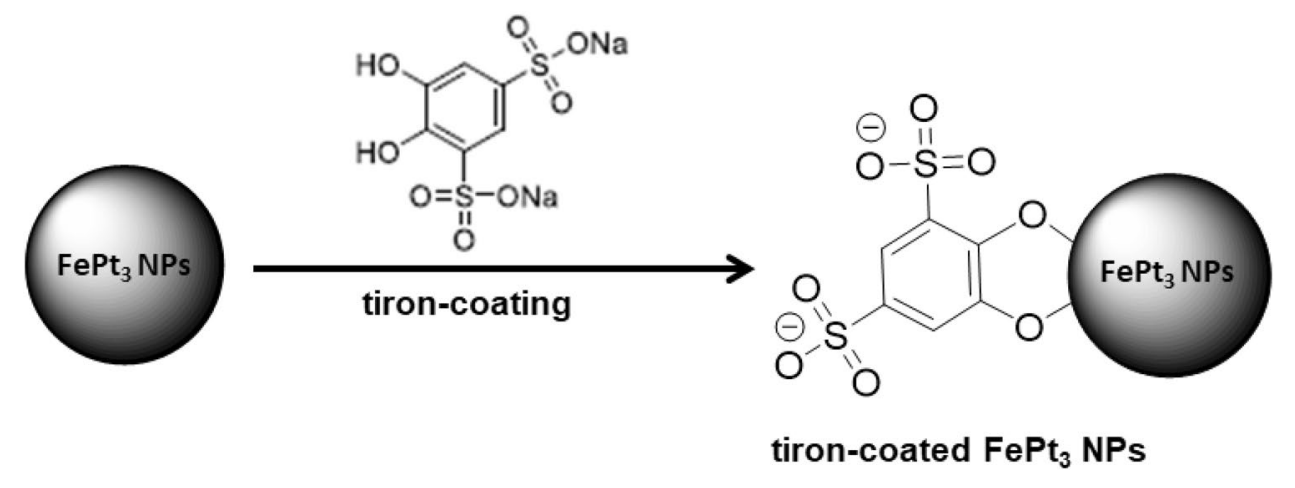

SN Applied Sciences A SPRINGER NATURE journal 


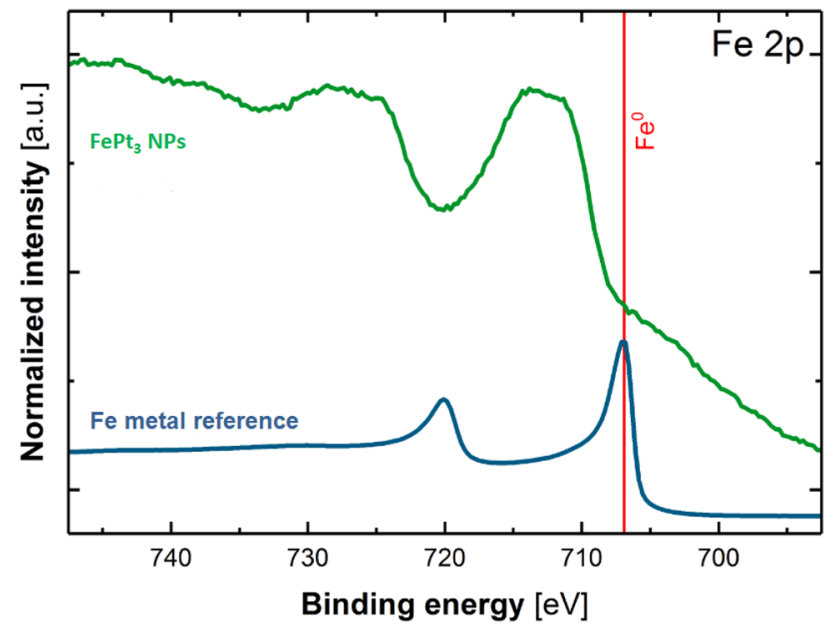

Fig. 6 Fe $2 p$ XPS spectrum of the FePt ${ }_{3}$ NPs

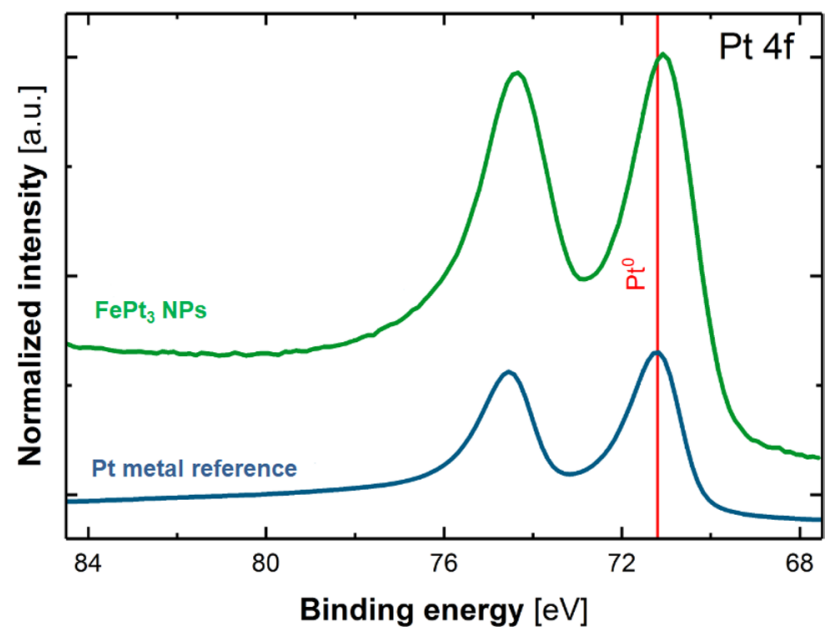

Fig. 7 Pt $4 f$ XPS spectrum of the $\mathrm{FePt}_{3} \mathrm{NPs}$

\subsection{Formation of $\mathrm{FePt}_{3}$ alloy nanoparticles}

The $\mathrm{FePt}_{3}$ alloy nanoparticles were synthesized via the thermal decomposition route at $320^{\circ} \mathrm{C}$ using $\mathrm{Fe}(\mathrm{acac})_{3}$ and oleylamine stabilized $\mathrm{Pt}^{2+}$ cations as $\mathrm{Pt}$ source. The formation of the chemically disordered $\mathrm{FePt}_{3}$ nanoparticles requires the co-reduction of $\mathrm{Fe}^{3+}$ and $\mathrm{Pt}^{2+}$ cations. Since $\mathrm{Pt}$ is a noble metal and $\mathrm{Fe}$ is a transition metal, the $\mathrm{Pt}^{2+}$ cations are faster reduced to $\mathrm{Pt}^{0}$ which sparks $\mathrm{Pt}$ nucleation. The Pt nuclei presumably catalyze the oleylamineinduced reduction of $\mathrm{Fe}^{3+}$ to $\mathrm{Fe}^{0}$ [2]. Subsequent nanoparticle growth occurs via the incorporation of Fe atoms into the Pt rich nuclei. The final size and stabilization are

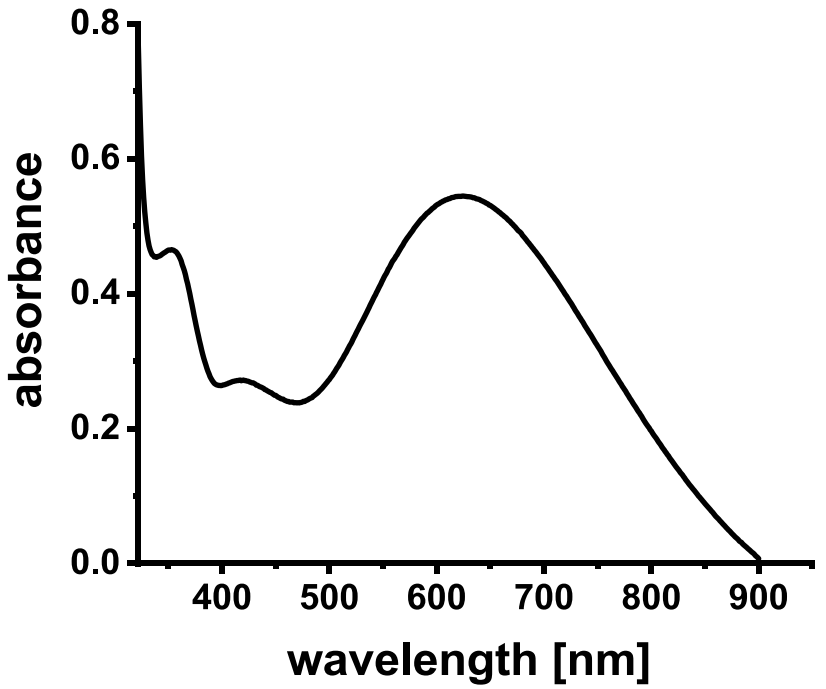

Fig. 8 UV-Vis absorption spectrum of tiron-coated $\mathrm{FePt}_{3} \mathrm{NPs}$ in water

adjusted by the precursor/oleyl acid (oleylamine) ratio. The final stoichiometric composition and structure of the $\mathrm{FePt}_{3}$ alloy nanoparticles follow from the reaction temperature as well as from the Fe and Pt precursor concentrations.

\section{Conclusions}

Our objective was to develop a highly scalable wetchemistry technique for the synthesis of processible, superparamagnetic $\mathrm{FePt}_{3} \mathrm{NPs}$ for versatile applications in electronics, catalysis and medicine. We elaborated a facile one-pot thermal decomposition procedure for the preparation of $10 \mathrm{~nm}$-sized $\mathrm{FePt}_{3}$ nanocrystals which exhibit superparamagnetism. A straightforward subsequent ligand exchange procedure yielded watersoluble tiron-coated $\mathrm{FePt}_{3} \mathrm{NPs}$ suited for processing to thin magnetic films or for application as CT/MRI contrast agents.

The stoichiometry and structural properties of the $\mathrm{FePt}_{3} \mathrm{NPs}_{\text {s }}$ were elucidated using HRTEM, HAADF, STEMEDX, XPS and XRD. We could unambiguously show that $\mathrm{FePt}_{3}$ NPs with a mean size of $10 \mathrm{~nm}$ crystallize in the chemically disordered fcc phase with the space group $\mathrm{Fm} \overline{3} \mathrm{~m}$. The chemical disorder substantiated the superparamagnetism of the $\mathrm{FePt}_{3} \mathrm{NPs}$ as being evident from the hysteresis-less magnetization curve. The optical properties and ligand binding modi of tiron-coated $\mathrm{FePt}_{3}$ NPs were examined using UV-Vis absorption and FTIR transmission spectroscopy. The aqueous $\mathrm{FePt}_{3} \mathrm{NPs}_{\mathrm{s}}$ solution exhibits a broad absorption band around $650 \mathrm{~nm}$, 
Fig. 9 pH dependency of tiron in aqueous solution<smiles>O=S(=O)([O-])c1ccc(O)c(S(=O)(=O)[O-])c1O</smiles>

\section{acidic form $\lambda=230,290(\mathrm{~nm})$}

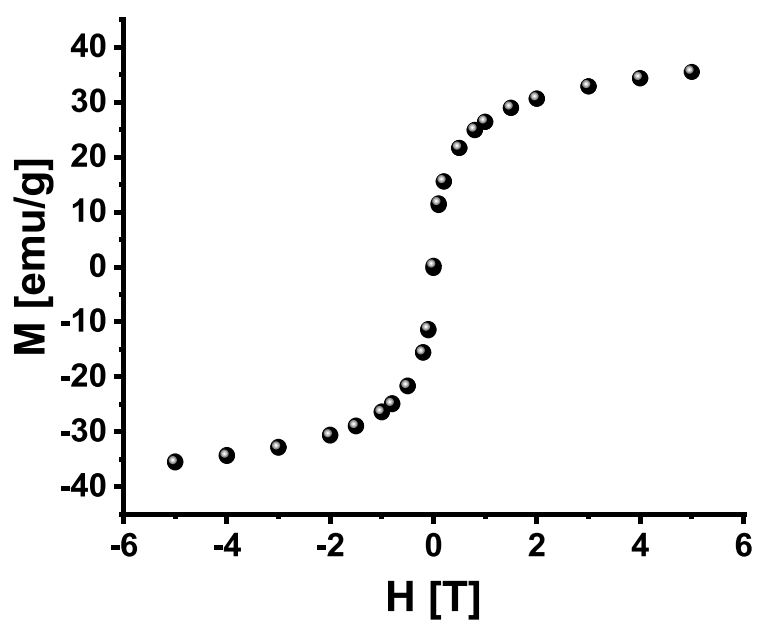

Fig. 10 Magnetization curve of tiron-coated $\mathrm{FePt}_{3} \mathrm{NPs}$

which is ascribed to an electron transfer from the $\mathrm{Pt}$ atoms to antibonding $\pi$-molecular orbitals of tiron which binds through its catechol moiety to the $\mathrm{FePt}_{3}$ surface. This particular optical property of tiron-coated $\mathrm{FePt}_{3} \mathrm{NPs}$ demonstrates the high catalytic potential of $\mathrm{FePt}_{3}$.

Acknowledgements The authors thank Dr. Sebastian Bochmann (Chair of Chemistry of Thin Film Materials, Friedrich-Alexander University of Erlangen-Nürnberg) and M.Sc. Julian Hümmer (Inorganic and General Chemistry, Friedrich-Alexander University of ErlangenNürnberg) for supporting the VSM-SQUID measurement. C. H. and
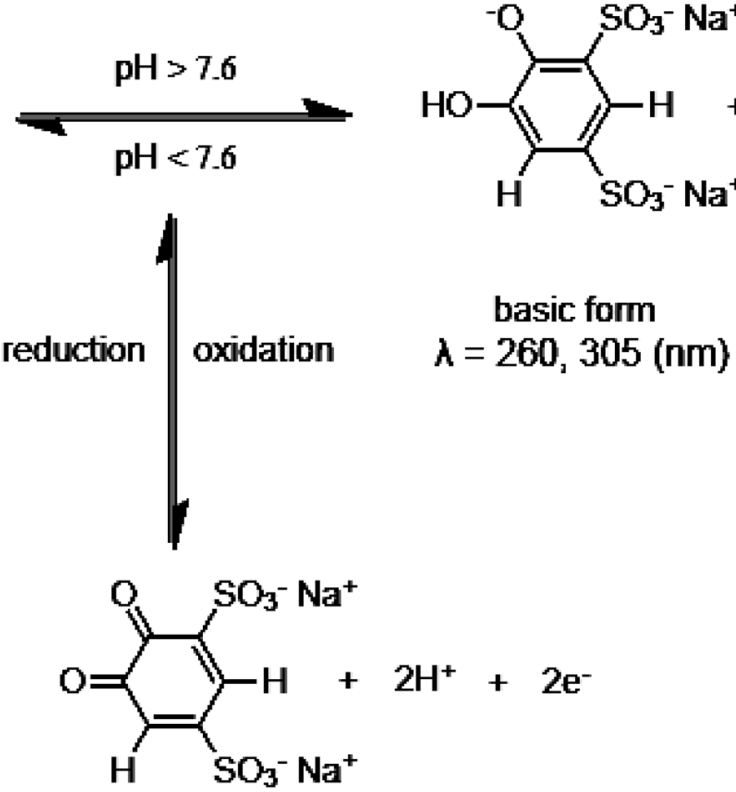

quinone

$\lambda=290,435(\mathrm{~nm})$

E. S. acknowledge financial support from the DFG through the Collaborative Research Center CRC953.

Funding Open Access funding enabled and organized by Projekt DEAL.

\section{Compliance with ethical standards}

Conflict of interest On behalf of all authors, the corresponding author states that there is no conflict of interest.

Open Access This article is licensed under a Creative Commons Attribution 4.0 International License, which permits use, sharing, adaptation, distribution and reproduction in any medium or format, as long as you give appropriate credit to the original author(s) and the source, provide a link to the Creative Commons licence, and indicate if changes were made. The images or other third party material in this article are included in the article's Creative Commons licence, unless indicated otherwise in a credit line to the material. If material is not included in the article's Creative Commons licence and your intended use is not permitted by statutory regulation or exceeds the permitted use, you will need to obtain permission directly from the copyright holder. To view a copy of this licence, visit http://creativecommons .org/licenses/by/4.0/.

\section{References}

1. Angelomé PC, Soler-Illia GJDA (2005) Organically modified transition-metal oxide mesoporous thin films and xerogels. Chem Mater 17:322-331

2. Chen S, Andre P (2012) Colloidal syntheses of FePt nanoparticles. Int J Nanotechnol 9:39-68 
3. Chen Y, Zhang H (2013) Complexation facilitated reduction of aromatic N-oxides by aqueous Fe"tiron com plex: reaction kinetics and mechanisms. Environ Sci Technol 47:1 1023-11031

4. Chou S-W, Yu-Hong Shau Y-H, Wu P-C, Yang Y-S, Shieh D-B, Chen C-C (2010) In vitro and in vivo studies of FePt nanoparticles for dualmodal CT/MRI molecular imaging. J Am Chem Soc 132:13271

5. De Berti IP, Cagnoli MV, Pecchi G, Alessandrini JL, Stewart SJ, Bengoa JF, Marchetti SG (2013) Alternative low-cost approach to the synthesis of magnetic iron oxide nanoparticles by thermal decomposition of organic precursors. Nanotechnology 24:175601

6. Fukuda K, Fujieda S, Shinoda K, Suzuki S, Jeyadevan B (2012) Low temperature synthesis of FePt alloy nano-particles by polyol process. J Phys: Conf Ser 352:012020

7. Gardner RR, Gerdes AL, Seeley JA (2013) Tiron-containing detergents having acceptable color, U.S. Patent No. 8, 399, 396. U.S. Patent and Trademark Office, Washington, DC

8. Green LA, Thuy TT, Mott DM, Maenosono S, Thanh NTK (2014) Multicore magnetic FePt nanoparticles: controlled formation and properties. RSC Adv 4:1039-1044

9. Heitsch AT, Lee DC, Korgel BA (2010) Antiferromagnetic single domain $\mathrm{L}_{2} \mathrm{FePt}_{3}$ nanocrystals. J Phys Chem C 114:2512-2518

10. Hori M, Pagnoux C, Baumard JF, Nogami M (2007) Preparation of gold nanoparticles (GNP) aqueous suspensions by a new method involving tiron. J Mater Sci 42:80-86

11. Hossain AA, Rahman ML (2011) Enhancement of microstructure and initial permeability due to $\mathrm{Cu}$ substitution in $\mathrm{Ni}_{0.50-\mathrm{x}} \mathrm{Cu}_{\mathrm{x}} \mathrm{Zn}_{0.50} \mathrm{Fe}_{2} \mathrm{O}_{4}$ ferrites. J Magn Magn Mater 323:1954-1962

12. Koch S, Ackermann G, Scholze V (1981) Untersuchungen zur Anwendung ternärer Komplexe in der Photometrie-II Die Bestimmung des Titanium (IV) mit Tiron in Gegenwart von Iminodiessigsäure, Nitrilotriessigsäure bzw. Diethylentriaminpentaessigsäure Talanta 28:915-918

13. Lee $Y$, Garcia MA, Frey Huls NA, Sun S (2010) Synthetic tuning of the catalytic properties of $\mathrm{Au}-\mathrm{FePt}_{3}$ nano-particles. Angew Chem 122:1293-1296

14. Liu $Y$, Jiang $Y$, Zhang $X$, Wang $Y$, Zhang $Y$, Liu H, Zhai H, Liu Y, Yang J, Yan $Y$ (2014) Structural and magnetic properties of the ordered $\mathrm{FePt}_{3}, \mathrm{FePt}_{\text {and }} \mathrm{Fe}_{3} \mathrm{Pt}$ nanoparticles. J Solid State Chem 209:69-73

15. Lutterotti $L$ (2010) Total pattern fitting for the combined sizestrain-stress-texture determination in thin film diffraction. Nucl Instrum Methods Phys Res B Beam Interact Mater At 268:334340. https://doi.org/10.1016/j.nimb.2009.09.053

16. Lutterotti L, Matthies S, Wenk HR, Schultz AJ, Richardson J (1997) Combined texture and structure analysis of deformed limestone from neutron diffraction spectra. J Appl Phys 81:594-600

17. Lutterotti L, Chateigner D, Ferrari S, Ricote J (2004) Texture, residual stress and structural analysis of thin films using a combined X-ray analysis. Thin Solid Films 450:34-41

18. Lutterotti L, Bortolotti M, Ischia G, Lonardelli I, Wenk HR (2007) Rietveld texture analysis from diffraction images. Z Kristallogr Suppl 26:125-130

19. McIntyre NS, Zetaruk DG (1977) X-ray photoelectron spectroscopic studies of iron oxides. Anal Chem 49:1521-1529

20. Medwal R, Sehdev N, Annapoorni S (2012) Electronic states of self-stabilized $L 1_{0}$ FePt alloy nanoparticles. Appl Phys $A$ 109:403-408

21. Meng Z, Li G, Ng SM, Wong HF, Yiu SC, Ho CL, Leung CW, Wong WY (2016) Nanopatterned L1 $1_{0}$-FePt nanoparticles from singlesource metallopolymer precursors for potential application in ferromagnetic bit-patterned media magnetic recording. Polym Chem 7:4467-4475
22. Mills P, Sullivan JL (1983) A study of the core level electrons in iron and its three oxides by means of $X$-ray photoelectron spectroscopy. J Phys D Appl Phys 16:723

23. Nguyen HL, Howard LEM, Stinton GW, Giblin SR, Tanner BK, Terry I, Hughes AK, Ross IM, Serres A, Evans JSO (2006) Synthesis of size-controlled fcc and fct FePt nanoparticles. Chem Mater 18:6414-6424

24. Ozutsumi K, Uchima Y, Kawashima T (1990) Structure of iron(III)Tiron complexes in aqueous solution. Anal Sci 6:573-577

25. Pana O, Leostean C, Soran ML, Stefan M, Macavei S, Gutoiu S, Pop V, Chauvet O (2013) Synthesis and characterization of FePt based multishell magnetic nanoparticles. J Alloys Compd 574:477-485

26. Poulin S, Franca R, Moreau-Bélanger L, Sacher E (2010) Confirmation of X-ray photoelectron spectroscopy peak attributions of nanoparticulate iron oxides, using symmetric peak component line shapes. J Phys Chem C 114:10711-10718

27. Preller T, Knickmeier S, Menzel D, Temel B, Garnweitner G (2020) Exchange bias in FePt-FePt $\mathrm{F}_{3}$ thin films by controlled phase transition of blended nanoparticle building blocks. Langmuir 36:2093-2101

28. Santos LRB, Chartier T, Pagnoux C, Baumard JF, Santillii CV, Pulcinelli SH, Larbot A (2004) Tin oxide nano particle formation using a surface modifying agent. J Eur Ceram Soc 24:3713-3721

29. Sarmphim P, Soontaranon S, Sirisathitkul C, Harding P, Kijamnajsuk S, Chayasombat B, Pinitsoontorn S, Chingunpitak J (2017) $\mathrm{FePt}_{3}$ nanosuspension synthesized from different precursors-a morphological comparison by SAXS, DLS and TEM. Bull Pol Acad Sci Tech 65:79-84

30. Sham TK, Yiu YM, Kuhn M, Tan KH (1990) Electronic structure of ordered and disordered $\mathrm{Cu}_{3} \mathrm{Au}$ : the behavior of the $\mathrm{Au} 5 \mathrm{~d}$ bands. Phys Rev B 41:11881

31. Simaan AJ, Boillot ML, Carrasco R, Cano J, Girerd JJ, Mattioli TA, Ensling J, Spiering H, Gütlich P (2005) Electronic, vibrational, and structural properties of a spin-crossover catecholato-iron system in the solid state: theoretical study of the electronic nature of the doublet and sextet states. Chem Eur J 11:1779-1793

32. Suber $L$, Imperatori P, Bauer EM, Porwal R, Peddis D, Cannas $C$, Ardu A, Mezzi A, Kaciulis S, Notargiacomo A, Pilloni L (2016) Tuning hard and soft magnetic FePt nanocomposites. J Alloys Compd 663:601-609

33. Sun S, Murray CB, Weller D, Folks L, Moser A (2000) Monodisperse FePt nanoparticles and ferromagnetic FePt nanocrystal superlattices. Science 287:1989-1992

34. Taher MA, Asadollahzadeh H, Fazelirad H (2015) Determination of trace amounts of iron by a simple fluore- scence quenching method. Anal Methods 7:6726-6731

35. Vlaic $P$, Burzo $E$ (2010) Magnetic behavior of iron-platinum alloys. J Optoelectron Adv Mater 12:1114-1124

36. Wilson D, Langell MA (2014) XPS analysis of oleylamine/oleic acid capped $\mathrm{FePt}_{3}$ nanoparticles as a function of temperature. Appl Surf Sci 303:6-13

37. Yamashita T, Hayes $\mathrm{P}$ (2008) Analysis of XPS spectra of $\mathrm{Fe}^{2+}$ and $\mathrm{Fe}^{3+}$ ions in oxide materials. Appl Surf Sci 254:2441-2449

38. Yao B, Peng C, Lu P, He Y, Zhang W, Zhang Q (2016) Fabrication of Tiron- $\mathrm{TiO}_{2}$ charge-transfer complex with excellent visible-light photocatalytic performance. Mater Chem Phys 184:298-305

39. Zheng Q, Zhang ZR, Du J, Lin LL, Xia WX, Zhang J, Bian BR, Liu JP (2019) A novel direct reduction method to synthesize ordered Fe-Pt alloy nanoparticles. J Mater Sci Technol 35:560-567

Publisher's Note Springer Nature remains neutral with regard to jurisdictional claims in published maps and institutional affiliations. 